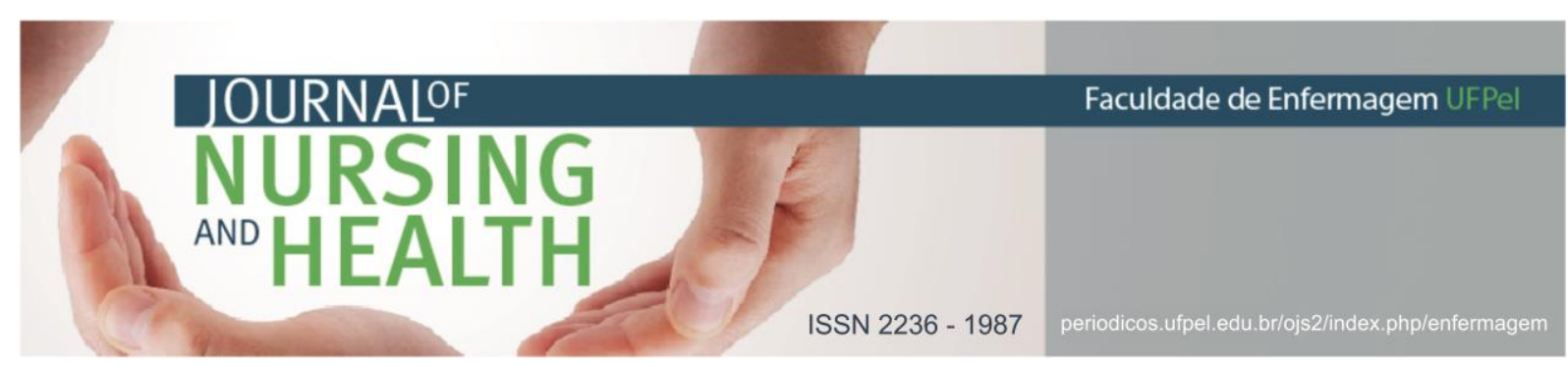

ENTREVISTA NARRATIVA

\title{
A experiência do grupo de ouvidores de vozes de Campinas como uma estratégia de transformação social: entrevista com Leonardo Duarte Bastos
}

The experience of the group of voices hearers from Campinas as a strategy of social transformation: interview with Leonardo Duarte Bastos

La experiencia del grupo de oyentes de voces de Campinas como una estrategia de transformación social: entrevista con Leonardo Duarte Bastos

Menezes, Etiene Silveira de ${ }^{1}$; Santos, Taís Rodrigues dos²; Kantorski, Luciane Prado ${ }^{3}$

Como citar este artigo: Menezes ES, Santos TR, Kantorski LP. A experiência do grupo de ouvidores de vozes de Campinas como uma estratégia de transformação social: entrevista com Leonardo Duarte Bastos. J. nurs. health. 2018;8(n.esp.):e188425

Palavras-chave: Saúde mental; Ouvir vozes; Participação social.

\section{APRESENTAÇÃOO}

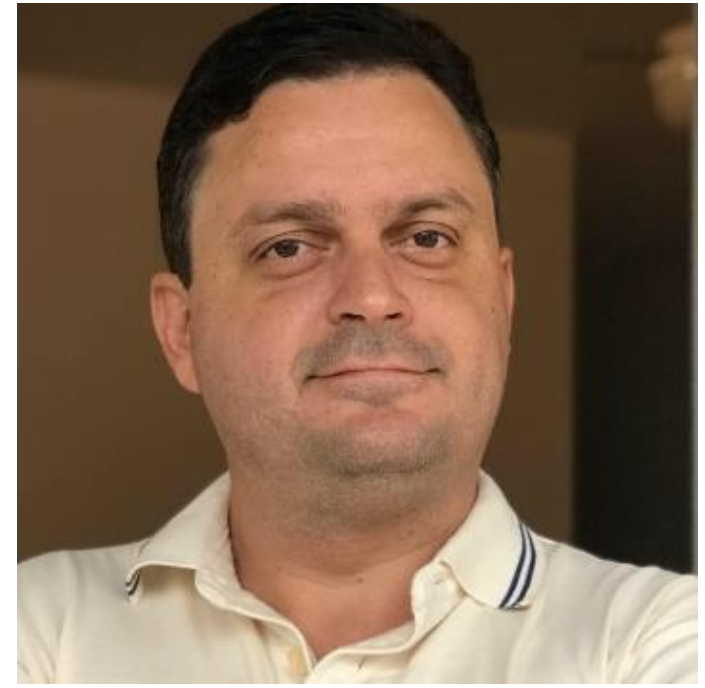

Esta entrevista contém a narrativa do psicólogo Leonardo Duarte Bastos, o qual atua como supervisor institucional em serviços e organizações ligadas à saúde mental e assistência social, conselheiro no Conselho Municipal de Assistência Social de Campinas, membro fundador do Grupo de Ouvidores de Vozes, diretor fundador do Instituto Conduzir, Coordenador de projetos na Cáritas de Campinas em ações voltadas para pessoas em situação de rua, também psicoterapeuta numa perspectiva psicodinâmica.

1 Enfermeira. Especialista em Enfermagem em Saúde Mental. Universidade Federal de Pelotas (UFPEL). E-mail: etimenezes@gmail.com http://orcid.org/0000-0003-3968-7260

2 Psicóloga. Especialista em Saúde da Família. Prefeitura Municipal de Pelotas. E-mail: taisrsantos23@gmail.com http: / / orcid.org/0000-0002-8208-8151

3 Enfermeira. Doutora em Enfermagem. Universidade Federal de Pelotas (UFPEL). E-mail: kantorski@uol.com.br http://orcid.org/0000-0001-9726-3162 


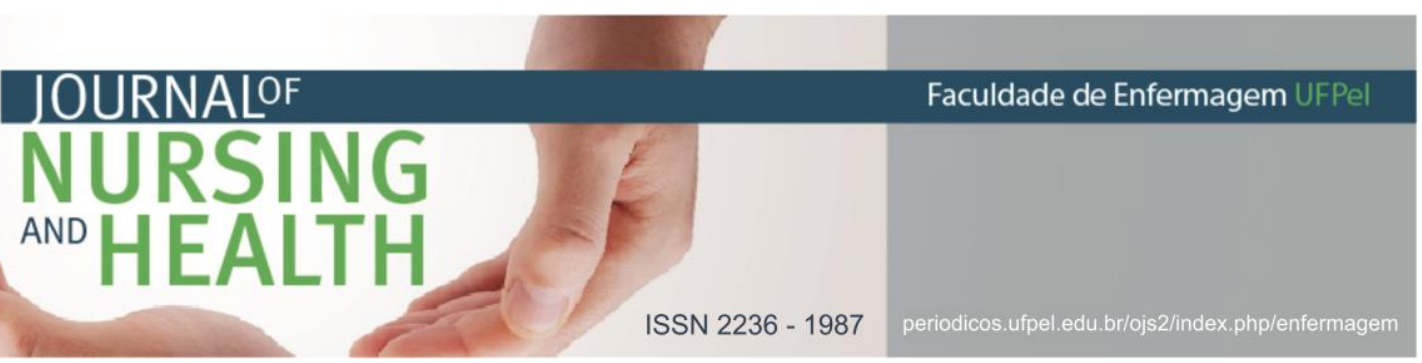

Trajetória: Iniciando o trabalho no serviço de acolhimento e estruturação dos grupos de ouvidores de vozes

$\mathrm{Na}$ minha trajetória eu começo a trabalhar diretamente com os ouvidores de vozes a partir de 2000. Eu trabalho dentro da política de assistência como psicólogo social com população adulta em situação de rua. É um serviço de acolhimento transitório e essas pessoas no tempo em que estão lá tem que procurar desenvolver essa autonomia e a gente tenta criar estratégias para poder lidar com a diversidade. No serviço de acolhimento a gente tenta construir estratégias para conviver de uma forma comunitária, ao mesmo tempo em que tentando desenvolver autonomia institucional. Existe uma grande incidência, dentro dessa população, de pessoas que ouvem vozes.

A gente teve experiências lá de várias pessoas ouvidoras de vozes que nos provocaram principalmente quanto a questão do medicamento, porque essas pessoas, na maior parte das vezes em que chegavam até a gente elas utilizavam uma quantidade grande de medicamentos e isso dificultava construir qualquer outro projeto de vida. E a medida que a gente conseguiu estruturar esse serviço para desenvolver ali uma convivência comunitária, a gente notou que essa convivência proporcionava uma harmonização dessas pessoas com as vozes, fazendo muitas vezes com que o médico do serviço externo que atendia ela fosse diminuindo a medicação. E nós tivemos várias experiências de pessoas que a partir do momento que entrava lá chegava a zerar a quantidade de medicação e que as vozes não eram um problema para essas pessoas.

Em 2014 foi quando a gente conheceu o Paul Baker e começamos a estabelecer algumas trocas. Em 2015, no começo de março, nós fizemos uma formação sobre os ouvidores de vozes e resolvemos montar um grupo, além de utilizar os conceitos pilares dos ouvidores de vozes que é a "despatologização", entender o ouvir vozes como experiência humana, começamos a utilizar no serviço de acolhimento lá onde nós trabalhávamos. No caso, na época, dois serviços de acolhimento, um serviço de acolhimento feminino e um masculino, montamos o grupo de ouvidores de vozes dentro dessa perspectiva.

\section{Produção e inter-relação dos saberes}

Existe uma resistência muito grande de trazer o saber acadêmico para a comunidade de uma forma mais horizontal. Existe um movimento que agora está sendo desmontado, que é o da Educação Popular em Saúde, um Departamento dentro do Ministério da Saúde que trabalhava com isso, de valorizar os saberes populares, o conhecimento da comunidade, na produção do cuidado e da qualidade em saúde. Isso encontra uma resistência muito grande no meio acadêmico que ainda se acha detentor do saber sobre a experiência do outro, então a gente tem essa vertente também muito forte que influencia nossas práticas.

A experiência daquele que ouve vozes é muito importante e precisa ter o mesmo nível de importância do que daquele que vai sistematizar, vai pensar e que 


\section{JOURNALOF \\ ISSN 2236 - 1987}

traz um conteúdo mais acadêmico. Então é nesse encontro entre quem ouve e quem não ouve, ou de várias pessoas que ouvem vozes que o conhecimento se produz.

\section{A identidade do grupo}

Uma das coisas que a gente utilizava nesse serviço de acolhimento que passou a dar identidade para esse grupo de ouvidores de vozes é Paulo Freire, principalmente a educação popular da produção horizontal do conhecimento, ou seja, não existe um doutor, alguém que sabe e alguém que não sabe que precisa ser cuidado, mas sim um encontro de pessoas com saberes diferentes e a gente começa a estruturar os grupos nessa linha. Tem um grupo que eu faço parte e tenho insistido bastante junto com o pessoal que assuma algumas atividades, mas ele não tem uma coordenação definida, aquele que está mais ativo naquele momento, ele coordena aquela atividade, aquele que tem mais experiência naquele momento, naquele assunto, no que vai se fazer, ele vai direcionar.

0 grupo tem duas vertentes muito importantes: uma é fortalecer os ouvidores de vozes, que é para dentro, através da troca de experiência, de experiências positivas de como lidar com as vozes e uma que é para fora, que é trabalhar na sociedade com a "desestigmatização". Se a gente entende que o sofrimento maior de quem ouve vozes se dá por conta do preconceito, se dá por conta da maneira como a nossa sociedade se organiza valorizando determinados grupos e desvalorizando outros, então as estratégias dos grupos de ouvidores de vozes não podem ser só para dentro, mas também de uma transformação social, senão eu estou culpabilizando essas pessoas ${ }^{1}$.

Então o grupo tem uma vertente muito forte de fazer diálogos com a sociedade: participação em rádio, organização de mobilizações, como a participação do grito dos excluídos, nós fizemos uma sessão na Câmara no dia mundial dos ouvidores de vozes. Esse diálogo com a sociedade também é muito importante.

Uma outra coisa que para gente é importante é que o grupo tenha uma independência em relação aos serviços de saúde, uma vez que não é uma parte do serviço de saúde, não é uma estratégia terapêutica, portanto não deve ser uma parte deste serviço.

A ideia da INTERVOICE (The International Network for Training, Education and Research into Hearing Voices), do movimento internacional, é ser um movimento social e não uma estratégia terapêutica, então a gente procurou incorporar bastante isso ${ }^{2}$.

\section{REFERÊNCIAS}

1 Kantorski LP, Antonacci MH, Andrade APM de, Cardano M, Minelli M. Grupos de ouvidores de vozes: estratégias e enfrentamentos. Saúde debate [Internet]. 2017 [acesso em 2018 set 10];41(115):1143-55. Disponível em: http: / / www.scielo.br/scielo.php?script=sci_arttext\&pid=S0103-11042017000401143 


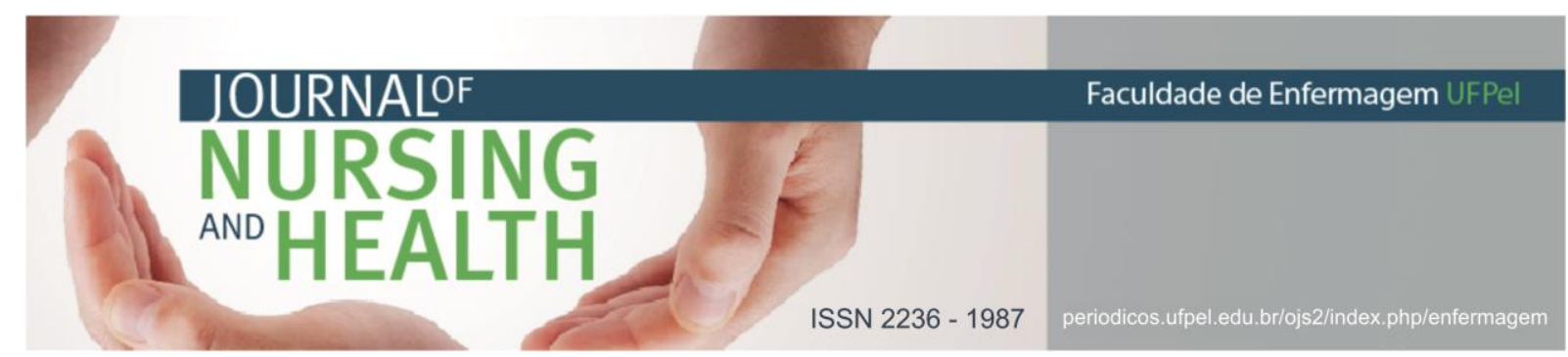

2 Kantorski LP, Andrade, APM de, Cardano M. Estratégias, expertise e experiências de ouvir vozes: entrevista com Cristina Contini. Interface comun saúde educ [Internet]. 2017 [acesso em 2018 set 10];21(63):1039-48. Disponível em: http://www.scielo.br/pdf/icse/v21n63/1807-5762-icse-21-63-1039.pdf

Data de publicação: 19/09/2018 